\title{
A Fibrina rica em plaquetas e leucócitos-L-PRF na Odontologia: revisão de
}

\section{literatura}

\author{
Fibrin rich in platelets and leukocytes-L-PRF- in Dentistry: literature review \\ Rico em fibrina en plaquetas y leucócitos-L-PRF en Odontología: revisión de la literatura
}

Recebido: 16/08/2021 | Revisado: 22/08/2021 | Aceito: 31/08/2021 | Publicado: 03/09/2021

\author{
Kadydja Laryssa Costa \\ ORCID: https://orcid.org/0000-0003-3686-9798 \\ Centro Universitário Tiradentes Pernambuco, Brasil \\ E-mail: kadydjalrb@gmail.com \\ Marcone de Vasconcelos Santos \\ ORCID: https://orcid.org/0000-0003-2965-3980 \\ Centro Universitário Tiradentes Pernambuco, Brasil \\ E-mail: marconvs@hotmail.com \\ Maria Dayane Da Silva Santos \\ ORCID: https://orcid.org/0000-0001-7358-9117 \\ Centro Universitário Faculdade Integrada de Patos, Brasil \\ E-mail: mari.dayane@outlook.com
}

\begin{abstract}
Resumo
Os procedimentos cirúrgicos são intervenções que visam reabilitar função e fisiologia de algum seguimento, lançando-se mão de técnicas que são, namaioria das vezes, muito invasivas e que geram uma situação de desconforto ao paciente. Em virtude disso, iniciou-se uma série de estudos sobre aditivos cirúrgicos que auxiliem no processo de cura de procedimentos, inclusive odontológicos. O plasma rico em fibrina (PRF) foi desenvolvido por Choukroun para ser usado em cirurgia oral e maxilofacial e, no campo da odontologia, possui vários domínios de aplicação, como levantamento do seio maxilar, enxerto de alvéolos, cirurgias periodontais estéticas, entre outros. O objetivo principal do presente estudo é realizar uma revisão de literatura como ferramenta para análise de um concentrado de plaquetas, descrevendo sua evolução até um novo modelo de aditivo cirúrgico bioativo (L-PRF), que ajude na cicatrização de lesões cirúrgicas e em outros procedimentos odontológicos por suas características de regeneração tecidual e de regulação inflamatória. Por se tratar de um procedimento barato e com grandes benefícios, a sua utilização em cirurgia oral e maxilofacial, deve ser considerada como uma opção clínica de grande interesse.
\end{abstract}

Palavras-chave: Plaqueta; Regeneração; Odontologia.

\begin{abstract}
Surgical procedures are interventions that aim to rehabilitate function and physiology of some follow-up, using techniques that are, in most cases, very invasive and that generate a situation of discomfort to the patient. As a result, a series of studies on surgical additives that assist in the process of curing procedures, including dental procedures, began. Fibrin-rich plasma (PRF) was developed by Choukroun for use in oral and maxillofacial surgery and, in the field of dentistry, it has several domains of application, such as maxillary sinus lifting, alveolar graft, aesthetic periodontal surgery, among others. The main objective of this study is to perform a literature review as a tool for analyzing a concentrate of platelets, describing their evolution to a new surgical additive model bioactive (L- PRF), which helps in the healing of surgical lesions and other dental procedures due to its characteristics of tissue regeneration and inflammatory regulation. As it is an inexpensive procedure with great benefits, its use in oral and maxillofacial surgery should be considered as a clinical option of great interest.
\end{abstract}

Keywords: Platelets; Regeneration; Dentistry.

\section{Resumen}

Los procedimientos quirúrgicos son intervenciones encaminadas a rehabilitar la función y fisiología tras algún seguimiento, utilizando técnicas que son, en la mayoría de los casos, muy invasivas y que generan una situación de malestar para el paciente. Como resultado, se iniciaron una serie de estudios sobre aditivos quirúrgicos que ayudan en el proceso de curación de los procedimientos, incluidos los procedimientos dentales. El plasma rico en fibrina (PRF) fue desarrollado por Choukroun para su uso en cirugía oral y maxilofacial y, en el campo de la odontología, tiene varios dominios de aplicación, como la elevación del seno maxilar, otros procedimientos quirúrgicos, incluido el injerto periodontal. El objetivo principal del presente estudio es realizar una revisión de la literatura como herramienta para el análisis de un concentrado de plaquetas, describiendo su evolución hacia un nuevo modelo de aditivo quirúrgico bioactivo (L-PRF), que ayuda en la cicatrización de otras cirugías. procedimientos y lesiones. por sus 
características de regeneración tisular y regulación inflamatoria. Al tratarse de un procedimiento económico y con grandes beneficios, su uso en cirugía oral y maxilofacial debe considerarse como una opción clínica de gran interés.

Palabras clave: Plaquetas; Regeneración; Odontologia.

\section{Introdução}

A literatura recente busca, por meio de estudos científicos, otimizar a neoformação óssea na área da saúde. O aumento da expectativa de vida tem como uma de suas consequências o crescimento na quantidade de pessoas desdentadas e tais pessoas estão mais rigorosas quando se trata de bem-estar, conforto e saúde.

A busca por tratamentos odontológicos que reabilite e proporcione conforto é unânime em virtude das falhas de próteses removíveis convencionais, por isso a procura pela implantodontia é frequente. Entretanto, a maior parte desses pacientes que buscam por este tipo de tratamento exibem situações insatisfatórias em relação à quantidade de osso e tornam o tratamento difícil e, algumas vezes, contraindicado.

Em virtude do avanço das técnicas e materiais que atuem na regeneração óssea houve o surgimento da Fibrina Rica em Plaquetas e Leucócitos (L-PRF). Dos biomateriais autógenos introduzidos na Odontologia, o L-PRF apresenta bons resultados na regeneração de tecidos lesados. É obtido do sangue humano por uma técnica simples, sem manipulação bioquímica e sem a utilização de anticoagulantes. O processo se baseia na obtenção de amostras do sangue que é coletado antes da cirurgia.

A partir de um processo físico obtém-se o L-PRF, utilizado para diversos fins na Odontologia, como acelerar o processo de reparo tecidual e reduzir o desconforto pós-operatório. O composto também tem como papel auxiliar no crescimento e na restauração de tecidos através da fibrina em matriz e plaquetas. De forma gradativa citocinas e fatores de crescimento relevantes na inflamação e no reparo são mobilizadas para atuarem em nível celular e auxiliar o crescimento dos tecidos. Justificada a importância do L-PRF na Odontologia atual, este estudo tem como objetivo geral realizar uma revisão de literatura acerca da utilização do L- PRF em procedimentos odontológicos. Como objetivos específicos, busca tecer apontamentos sobre a evolução dos adjuvantes cirúrgicos; demonstrar o protocolo de obtenção do L-PRF; apontar os principais usos do L-PRF na Odontologia.

\section{Metodologia}

Decidiu-se por realizar uma revisão de literatura, cujo objetivo foi possibilitar reflexões quanto às possibilidades de utilização da PRF. A pesquisa se deu através da busca livre dos descritores e/ou de suas combinações: "fibrina"; "plaquetas"; "odontologia"; nas bases de dados Scielo, Pepsic, IndexPsi, LILACS, Biblioteca Digital Brasileira de Teses e Dissertações (BDTD) e Google Scholar.

Para compor a seleção das produções, foram considerados os artigos, teses, dissertações e trabalhos apresentados em eventos científicos que abrangessem o contexto brasileiro e/ou o internacional, em língua portuguesa ou inglesa, e a delimitação do período de publicação entre 2001 e 2020. Foram encontrados 44 artigos no total, utilizando-se os descritores citados no parágrafo anterior. Dentre eles, 21 foram selecionados por se encaixarem nos critérios de exclusão supraelencados.

Neste estudo, entende-se que o método de revisão da literatura tem como pressuposto a contextualização de temática e sua subsequente análise e problematização, a partir da leitura e análise das produções encontradas. Foi realizada a leitura crítica dos materiais, buscando-se a construção e o aprofundamento dos fundamentos teóricos para embasar a discussão da temática em estudo.

\section{Resultados e Discussão}




\subsection{Evolução dos aditivos cirúrgicos}

A cura de um ferimento se inicia pelos processos de coagulação e inflamação. Posteriormente, desencadeia-se uma fase de proliferação, que se inicia com o processo de epitelização e finaliza quando o colágeno se encontra devidamente depositado e maturado. Esse processo pode ser natural ou estimulado por adjuvantes cirúrgicos, que trabalham em prol da associação dos fatores de cura (Agrawal, 2014).

Tais aditivos realizam uma incitação da cicatrização, buscando acelerá-la, e se fundamentam em pesquisas científicas que consideram diversos fatores ensejadores do crescimento. Os isômeros utilizados na atualidade dividem-se em fator de crescimento plaquetário (PDGF - plateled-derived growth factor), que vem a ser o fator de crescimento derivado de plaquetas; $\mathrm{e}$ fatores de crescimento transformadores ( $T G F$ - transforming growth factor), que são o TGF- $\beta 1$ e TGF- $\beta 2$; fator de crescimento endotelial vascular (VEGF - vascular endothelial growth factor) e fator de crescimento epitelial (EGF - epidermal growth factor) (Vendramin, 2006).

O funcionamento se dá nos seguintes parâmetros: os TGF's iniciam ativando fibroblastos para a síntese do prócolágeno, tendo como resultado o processo de deposição do colágeno e de cicatrização do ferimento. Entram então, em cena, os PDGF's, em associação ou não com os fatores anteriores, promovendo que os tecidos se vascularizem, os fibroblastos se proliferem, a quantidade de colágeno aumente, o tecido de granulação tenha sua produção estimulada e a osteogênese ocorra em melhores condições (Vendramin, 2006).

Nesse momento, o VEGF estimula que ocorram angiogênese, mitogênese e permeabilidade mascular, enquanto o EGF se encarrega de incitar que o epitélio cresça, consequentemente também promovendo angiogênese.

Dessa maneira os fatores tornam o processo de cicatrização mais eficaz e acelerado, o que permite que enxertos possam ser integrados com maior facilidade em se tratando de diversos tecidos, tais como cutâneos, ósseos, cartilaginosos etc. (Vendramin, 2006).

\subsubsection{Cola de fibrina}

A cola de fibrina é tida como o primeiro adjuvante cirúrgico a ser empregado, tendo sua comercialização se iniciado na Europa, por volta de 1970 (Prakash, 2011). Esse elemento tem uma importante característica, que é reproduzir o final da cascata coagulatória, tendo uma ação independente mediante mecanismos coagulatórios internos - ensejando, assim, que o ferimento alcance a homeostase sem depender de defeitos coagulatórios (Prakash, 2011). Além disso, trata-se de um material atóxico e biodegradável, além de já possuir os benefícios de crescimento e reparação tecidual (Roy et al., 2004). Os principais empregos da cola dizem respeito à hemostasia local, regeneração tecidual e substituição de agentes ósseos (Prakash, 2011).

Existem dois tipos de cola de fibrina. O primeiro tipo diz respeito às colas comerciais, que são disponibilizadas como componentes preparatórios de dois subtipos, a saber, um concentrado de fator XXX, fibrinogênio e fibronectina em solução antifibrótica e um concentrado de trombina dissolvido em cloreto de cálcio. Quando os dois componentes são misturados, isso resulta num coágulo de fibrina, mimetizando a última fase da cascata coagulatória (Roy et al., 2004).

O segundo tipo de cola de fibrina se deu nos Estados Unidos, através de um biomaterial autólogo, que se pode sintetizar a partir do próprio plasma de um paciente (o que se mostra deveras seguro, em virtude do risco de infecção cruzada) (Roy et al., 2004). Suas aplicações clínicas dizem respeito a implantes dentários, defeitos osteoarticulares, regeneração óssea e cicatrização de ferimentos exodônticos.

Porém, esse tipo de cola é limitado por ter um maior índice de fraqueza e menor índice de resistência a fenômenos físicos, em comparação com o primeiro tipo de cola de fibrina. Sua eficácia é comprovada em tecidos moles, todavia, estudos ainda são realizados a fim de comprovar uma contribuição eficaz para a cirurgia periodontal (Prakash, 2011). 


\subsubsection{Primeira geração de concentrado plaquetário: o plasma rico em plaquetas}

Em 1998, iniciou-se uma tendência pelo emprego de tecnologias de concentrados plaquetários em odontologia (Marx et al., 2008). A sigla PRP, que significa plasma rico em plaquetas, foi empregada em 1954 por Kingsley, definindo um elemento com trombócitos concentrados, durante suas experiências coagulatórias em sangue. Quando se publicavam os primeiros estudos sobre as colas de fibrina, testou-se produtos ricos em plaquetas em várias áreas, especialmente nos campos da cirurgia geral e da oftalmologia (Ehrenfest et al., 2012). Sua utilização, todavia, não se deu necessariamente para estimular a cicatrização, mas como adesivos de fibrina. Não se consideraram, portanto, em tais aplicações, as propriedades curativas desses compostos (Ehrenfest et al., 2012).

O plasma rico em plaquetas é um produto com maior complexidade do que uma preparação farmacêutica comum, por possuir efeitos clínicos totalmente ligados às características de versatilidade e adaptabilidade do sangue do paciente. A biologia de um concentrado de plaquetas é igualmente complexa à biologia do próprio sangue, por serem, tecnicamente, concentrados de sangue (Prakash, 2011). O PRP se baseia de forma científica nos fatores de crescimento, uma vez que se sabe claramente seu papel imprescindível nos processos reparatórios teciduais, promovendo e modulando as funções celulares relativas ao processo de cicatrização e regeneração tecidual, tal como de proliferação celular (Prakash, 2011).

\subsubsection{Segunda geração de concentrado plaquetário: a fibrina rica em plaquetas e leucócitos}

A fibrina rica em plaquetas e leucócitos, conhecida pela sigla L-PRF, faz parte de uma segunda geração de concentrados plaquetários - e, dessa vez, incluindo-se fatores imunológicos. Seu processamento é simples e não exige manipulação sanguínea, e isso é um fator importante para que se determine a organização da rede de fibrina em suas três dimensões. (Choukroun et al.,2006; Dohan et al., 2006).

Em 2000, Choukroun foi o responsável pelo surgimento do L-PRF, na França, a fim de sua utilização em cirurgias da cavidade oral. No processo, não se utilizam trombina nem fatores anticoagulantes. Pela ausência destes últimos, a maioria das plaquetas é rapidamente ativada, liberando assim a cascata coagulatória com maior celeridade (Souza et al., 2016).

Não se pode identificar a fibrina leucoplaquetária autóloga como um hemoderivado típico, por não ter funções transfusionais, conceito comumente empregado na área hospitalar. Trata-se de um elemento de emprego essencialmente autólogo (Oliveira et al., 2018). Pode-se definir como uma matriz cicatricial, apresentando uma rede de fibrina com concentrado de plaquetas, ensejando uma eficiente capacidade regenerativa desencadeada pelas plaquetas, citocinas liberadas e fatores de crescimento unidos no coágulo de fibrina, com liberação gradativa, o que potencializa o reparo tecidual (Oliveira et al., 2018).

\subsection{Protocolo para obtenção do L-PRF}

A obtenção do L-PRF é bastante simples e possui baixo custo comparada a outros métodos. Inicia-se pela coleta do sangue em tubos de ensaio em plástico ou vidro, passando-se a centrifugá-los imediatamente (Fig. 1). 10 mililitros de sangue são retirados via punção venosa, no paciente, antes de realizar o procedimento cirúrgico. Após isso, a centrífuga, em 200G ou 400G rotações por minuto, promove a separação dos componentes sanguíneos durante cerca de 10 minutos, não havendo adição de anticoagulante ao material. (Dohan et al., 2006) Quanto mais imediata for a transferência do sangue, após a coleta, para a centrífuga, mais satisfatório é o resultado da técnica (Rodrigues et al., 2015).

O coágulo do L-PRF é sintetizado a partir da polimerização de forma natural, durante a centrifugação. Tal estrutura fibrinolítica é a ferramenta de liberação prolongada tanto de fatores de crescimento quanto de glicoproteínas, presentes na matriz durante um período que varia entre 14 e 21 dias. Pode-se observar clinicamente, após a centrifugação, a distinção de três camadas, a saber: soro na parte superior do recipiente, glóbulos vermelhos na parte inferior e, entre elas, o L- PRF, numa camada intermediária (Souza et al., 2016). 


\subsection{Utilização do L-PRF na odontologia}

Em um estudo apresentado por Yo-Chao et al. (2011), citam-se de dois casos de defeitos ósseos numa paciente de 38 anos. Realizaram-se cirurgias nos elementos dentários 27 e 36, empregando-se a membrana de L-PRF em seu fechamento. Pós-cirurgicamente, em avaliações 90 e 180 dias depois da cirurgia, pôde-se verificar que o ligamento periodontal foi reinserido e a bolsa periodontal eliminada, mostrando-se, então, que o L-PRF ensejou a regeneração periodontal.

Foram avaliadas por Tunali et al. (2015) a utilização de membranas de L- PRF no lugar de enxertos de tecido conjuntivo livre a fim de tratar anomalias em recessão gengival. Os autores selecionaram 44 recessões gengivais, sendo elas das classes I e II de Miller, bilaterais e com tamanho maior que 3 milímetros. No período de 1 ano, houve um índice de cobertura radicular idêntico tanto no grupo de teste do L-PRF quanto no grupo controle, demonstrando que a membrana de LPRF é uma alternativa eficaz para enxertos com o objetivo de tratar múltiplas recessões gengivais, dispensando cirurgias adicionais.

Posteriormente, teceu-se um estudo avaliativo em 40 pacientes, realizado por Femminella et al. (2016). Tais pacientes demonstravam pelo menos um local de recessão gengival classe I ou II de Miller. Seu tratamento foi realizado com um retalho coronalmente avançado e com enxerto de tecido conjuntivo. Tratou-se de duas formas o desconforto da zona doadora: no grupo de teste, colocou-se uma membrana de L-PRF nos ferimentos palatinos; já no controle, foi utilizada gelatina absorvível no tratamento dos pacientes. Monitoraram-se os pacientes nos 30 dias posteriores às cirurgias de re-epitelização dos ferimentos. Como resultado, os pacientes do grupo de teste tiveram cicatrização mais rápida do que os do grupo controle, em média com 1 semana de diferença destes, além de terem relatado menos desconforto e também utilizado menos analgésicos.

\subsubsection{Em enxertos no seio maxilar}

Realizou-se um estudo por Choukroun et al. (2006) em seis levantamentos de seio maxilar, nos quais utilizou-se osso liofilizado e L-PRF. Os autores afirmaram que a maturação óssea aconteceu em 4 meses após o enxerto. No mesmo trabalho, afirmou-se que, em caso de a membrana sinusal se romper acidentalmente, o L-PRF pode ser utilizado para vedação e reestabelecimento da membrana rompida, em virtude de possuir elasticidade e ser resistente, condicionando a continuação do levantamento de seio sem mais interferências.

Por sua vez, Simonpieri et al., em 2011, estudaram o levantamento e o posicionamento de implantes apenas com enxerto de L-PRF em 23 levantamentos de seio maxilar e 53 implantes, em 20 pacientes. Após 6 meses de acompanhamento desses pacientes, todos estavam clinicamente estáveis durante o aperto da prótese, nenhum implante apresentou problemas durante seis anos de acompanhamento e o ganho ósseo foi de 8,5 a 12 milímetros. Concluiu-se então que o PRF-L, como único material de preenchimento e colocação de implantes simultaneamente, é uma opção cirúrgica viável e que o PRF-L promove a regeneração natural do osso.

No estudo de Tajima et al. (2013), analisaram-se 17 pacientes nos quais foi utilizado apenas o enxerto de L-PRF no levantamento de seio maxilar. Houve a osteointegração em todos eles. Analisando-se sua formação óssea, a partir de radiografias e scans tomográficos, pôde-se comprovar que a formação óssea se deu de forma eficaz e que a osseointegração completa foi concluída após 6 meses da inserção dos enxertos. Concluiu-se que o emprego do L-PRF como material de preenchimento estimulou a formação óssea.

\subsection{Em alvéolos frescos pós-exodontia}

A técnica foi descrita por Choukroun et al. (2006) e Dohan et al. (2006), explicando que há uma mudança rápida na estrutura óssea logo após a exodontia, ocorrendo a reabsorção do osso e, por vezes, dificultando que se coloquem implantes. 
Todavia, segundo os autores, quando ocorre a colocação imediata do implante, pode-se evitar a perda de estrutura óssea. Também, a remodelação alveolar e a osteointegração ocorrem juntas, preservando ao máximo a função estética. Por ter uma manipulação sanguínea simples e prática, o L-PRF traz uma regeneração mais acelerada da unidade óssea, acelerando assim também a epitelização, mediante a estimulação de fibronectina e vibronectina.

Em um ensaio clínico randomizado, Marenzi et al. (2015) analisaram 108 casos de exodontias, tendo cada paciente entre dois e oito casos, e puderam observar que o grupo de teste do L-PRF passou por uma melhor administração do processo inflamatório, com menos queixas acerca de dor e edemaciação, tendo isso possibilitado uma epitelização mais eficaz e eficiente, contribuindo-se assim para uma regeneração mais adequada.

As complicações pós-operatórias de exodontias de terceiros molares foram avaliadas por Canellas, Ritto e Medeiros (2017) com o uso de L-PRF. Em sua análise, as autoras apresentaram que a prevalência da osteíte alveolar decorrente dessa exodontia diminuiu em 95\% com a utilização de L-PRF no pós-operatório, pelo fato de a membrana ter acelerado o processo regenerativo.

\subsection{Vantagens do uso do L-PRF}

Choukroun et al. (2006), Dohan et al. (2006), Naik et al. (2013) e Kawase et al. (2015) concordam que a utilização de L-PRF é uma técnica fácil, acessível e efetivamente contribui para um melhor pós-operatório dos pacientes submetidos a esse método. Dohan et al. (2006) e Simonpieri et al. (2011) afirmam que uma das vantagens principais do L-PRF é sua facilidade de obtenção em apenas um passo de centrifugação e sem manipulação bioquímica. Choukroun et al. (2006) afirmam ser o LPRF um material vantajoso por ser obtido de sangue autólogo. Dohan et al. (2006) relata não haver risco de reação imunológica no uso de L-PRF pelo fato de não ser adicionada a trombina em sua gênese, tornando assim a polimerização um processo natural. Para Kawase et al. (2015), a regeneração é efetivamente estimulada pelo fatode a rede de fibrina natural permanecer por um bom tempo. Choukroun et al. (2006) e Simonpieri et al. (2011) afirmam que o L-PRF pode ser utilizado sozinho ou em combinação com outros enxertos, a fim de acelerar o processo de cicatrização.

\subsection{Desvantagens da utilização do L-PRF}

O sangue precisa sempre ser colhido rapidamente e colocado para centrifugar (Choukroun et al., 2006). É necessário sempre utilizar-se tubo de vidro (Dohan et al., 2006).

\section{Conclusão}

O L-PRF é um concentrado de fatores de crescimento de fácil obtenção e baixo custo; Promove a angiogênese, a migração e proliferação celular e pela presença leucocitária modula o processo inflamatório em seu tempo e intensidade;Favorece a formação óssea, quando combinado a outros materiais de enxertia;Favorece a cicatrização dos tecidos moles, atuando no processo inflamatório;Favorece a cicatrização em alvéolos e locais de remoção do enxerto gengival, causando menor morbidade e uma cicatrização mais rápida;Pesquisas futuras ainda são necessárias para avaliar o efeito adicional sobre as técnicas de enxertia óssea.

\section{Referências}

Agrawal, V. (2014) Platelet rich fibrin and its applications in dentistry: a review article. National Journal of Medical and Dental Research, 2(3), 51-58

Canellas, J. V. D. S., Ritto, F. G. \& Medeiros, P. J. D. Evaluation of postoperative complications after mandibular third molar surgery with the use of plateletrich fibrin: a systematic review and meta-analysis. Int. J. Oral Maxillofac. Surg. 46(9) 
Research, Society and Development, v. 10, n. 11, e332101119473, 2021

(CC BY 4.0) | ISSN 2525-3409 | DOI: http://dx.doi.org/10.33448/rsd-v10i11.19473

Choukroun, J. et al. (2006). Platelet-rich fibrin (PRF): a second-generation platelet concentrate. Clinical effects on tissue healing. Oral Surg. Oral Med. Oral Pathol. Oral Radiol. Endod. 101(3)

Dohan, D. M. et al. Platelet-rich fibrin (PRF): a second-generation platelet concentrate. Leucocyte activation: a new feature for platelet concentrates? Oral Surg. Oral Med. Oral Pathol. Oral Radiol. Endod., 101(3).

Ehrenfest, D. M. D. et al. Three Dimensional Architecture and Cell Composition of a Choukroun's Platelet-Rich Fibrin Clot andMembrane. J. Periodontol., 81(4).

Femminella, B. et al. Clinical comparison of platelet-rich fibrin and a gelatina sponge in the management of palatal wounds after epithelialized free gingival graft harvest: a randomized clinical trial. J. Periodontol., 87(2).

Hoaglin, D. R., \& Lines, G. K. Prevention of localized osteitis in mandibular thirdmolar sites using platelet-rich fibrin. Int. J. Dent., 2013.

Kawase, T. et al. The heat-compression technique for the conversion of plateletrich fibrin preparation to a barrier membrane with a reduced rate of biodegradation. J. Biomed. Mater. Res. B Appl. Biomater., 103(4).

Kulkarni, M. R. et al. Platelet-rich fibrin as an adjunct to palatal wound healing after harvesting a free gingival graft: a case series. J. Indian Soc. Periodontol., $18(3)$.

Marenzi, G. et al. Influence of Leukocyte- and Platelet-Rich Fibrin (L-PRF) in the healing of simple postextraction sockets: a split-mouth study. Biomed. Res. Int.

Naik, B. et al. Role of Platelet rich fibrin in wound healing: a critical review. J. Conserv. Dent., 16(4).

Mark, R. E. et al. Tissue Engineering: applications in maxillofacial surgery and periodontics. Illinois: Carol Strean.

Oliveira, M. R. et al. Influence of the association between platelet-rich fibrin and bovine bone on bone regeneration. A histomorphometric study in the calvaria of rats. Int. J. Oral Maxillofac. Surg., 44(5).

Prakash, S. Platelet concentrates: past, present and future. Association of Oral and Maxillofacial Surgeons, 10(1).

Roy L. T. J. et al. Autologous Fibrin Glue: The Last Step in Operative Hemostasis. Burlingame, 168.

Simonpierri, A. et al. Simultaneous sinus-lift and implantation using microthreaded implants and leukocyte and platelet-rich fibrin as sole grafting material: a six-year experience. Implant Dent., 20(1),

Tajima, N. et al. Evaluation of sinus floor augmentation with simultaneous implant placement using platelet-rich fibrin as sole grafting material. Int. J. Oral Maxillofac. Implants, 28(1)

Tunali, M. et al. Clinical evaluation of autologous platelet-rich fibrin in the treatment of multiple adjacent gingival recession defects: a 12 -month study. Int. $J$. Periodontics Restorative Dent., 35

Vendramin, F. S. Plasma rico em plaquetas e fatores de crescimento: técnica de preparo e utilização em cirurgia plástica, Rev. Col. Bras. Cir., 33 , $24-28$.

Wani, A. L., Ara, A., \& Bhat, S. A. Blood injury and injection phobia: the neglected one. Behav. Neurol. 